\title{
Quaderni
}

QUADERNI Communication, technologies, pouvoir

68 | Hiver 2008-2009

Militantisme médical et fabrique des politiques de santé

\section{Orphan Drugs, Patient Activism and Contemporary Healthcare}

Drogues orphelines, militantisme médical et soins de santé contemporains

\section{Carlos Novas}

\section{(2) OpenEdition}

\section{Journals}

Electronic version

URL: http://journals.openedition.org/quaderni/262

DOI: $10.4000 /$ quaderni.262

ISSN: 2105-2956

\section{Publisher}

Les éditions de la Maison des sciences de l'Homme

\section{Printed version}

Date of publication: 5 January 2009

Number of pages: $13-23$

\section{Electronic reference}

Carlos Novas, « Orphan Drugs, Patient Activism and Contemporary Healthcare », Quaderni [Online], 68 | Hiver 2008-2009, Online since 05 January 2012, connection on 01 May 2019. URL : http:// journals.openedition.org/quaderni/262 ; DOI : 10.4000/quaderni.262 


\title{
$D$ ossier
}

\author{
orphan \\ This paper examines the forms of political \\ activism that have emerged around orphan drugs \\ drugs, \\ from the late 1970 s to the contemporary present. \\ The first paper of the paper will illustrate how \\ the problem of developing drugs aimed at \\ patient \\ actvism \\ and

\section{contemporary healthcare} \\ Carlos \\ Novas \\ Assistant Professor \\ Department of Sociology \\ and Anthropology \\ Carleton University \\ treating rare diseases was made knowable to \\ political authorities in the United States through \\ a combination of patient group activism, \\ congressional hearings, surveys, academic \\ conferences, and media reports. Through the \\ formation of an effective coalition, patients' \\ associations were able to aid the passage of \\ legislation specifically concerned with altering \\ the economic and regulatory circumstances that \\ previously prevented pharmaceutical companies \\ from developing treatments targeted at rare \\ diseases. In the second section of the paper, I \\ will move on discuss how the US Orphan Drug \\ Act (1983) has been adopted as a policy model \\ in a number of countries such as Singapore, \\ Japan, Australia, and most recently, throughout \\ european member states. The paper will examine \\ the impact that this legislation has had on the \\ biotechnology industry, which has benefited \\ considerably from the provisions contained \\ within orphan drug legislation. Lastly, the \\ paper will conclude by examining some of the \\ contemporary biopolitical problems that orphan \\ drugs pose in terms of the high cost of some \\ of these therapies. The emerging contours of \\ this problem consists of reconciling providing \\ expensive treatments for a small number of \\ patients whilst still trying to meet and finance the \\ healthcare needs of the general population. As \\ part of this examination, reference will be made \\ to the practices and forms of thought (health \\ technology assessment or pharmacoeconomics) \\ that are used to inform decisions regarding the
}


funding of medical treatments in contemporary European health care systems. Through this paper, I propose to examine how patient activism around orphan drugs has shifted from attempting to shape the economic and regulatory circumstances that prevented the marketing of orphan drugs to attempting to challenge the administrative and bureaucratic procedures that now prevent patients from having access to these therapies.

\section{Origins of the orphan drug problem}

The orphan drug problem illustrates how the advocacy efforts of patients' groups can extend beyond the scope of their illnesses and may encompass economic and regulatory policy (Epstein 1996; Rabeharisoa 2003). Orphan drugs refer to pharmaceutical or biological therapies intended for the treatment of rare diseases. Prior to the advocacy efforts of patients' groups, pharmaceutical companies had little financial incentive to invest in the research, development or marketing of drugs targeted at small patient populations. Beginning in the late 1970s, a number of patients' groups in the United States began to question the regulatory and economic circumstances that prevented the development or marketing of potentially therapeutically important drugs for rare diseases such as myoclunus, Tourette's syndrome, or Wilson's disease. The advocacy efforts of patients' groups primarily concentrated on the regulatory procedures at the U.S. Food and Drug Administration (FDA), in addition to the failure of pharmaceutical companies to invest in the development or marketing of orphan drugs.

Throughout the 1970s, some effort was made on the part of regulatory agencies within the U.S. bureaucracy to address the orphan drug problem through the formation of two inter-governmental committees (Asbury 1985). However, these committees met with limited success due to lack of agreement on what constituted orphan drugs and limited knowledge of drugs intended for small patient populations (Asbury 1985). It was not until the late 1970 s and early 1980 s that awareness of the orphan drug problem became widespread and a significant political issue due to the activism of a number of patients' organisations. One group that brought the orphan drug problem to the foreground was the National Myoclunus Foundation, a myoclunus sufferer named Sharon Dobkin, and an academic scientist, Dr. Melvin Van Woert. For many years they had tried to find a pharmaceutical company willing to develop and market a promising therapy for myoclonus known as L-5HP. Based on the lack of interest they encountered from the pharmaceutical sector and the state, they decided to attempt to influence policy around the orphan drug issue (Van Woert 1983). Towards this end, Sharon Dobkin contacted her elected official, Representative Elizabeth Holtzman. Based on hearing Dobkin's experience and that of Dr. Van Woert in trying to find a sponsor for L-5HP, on April 23, 1980, Holtzman introduced a Bill in Congress proposing the creation of an Office of Drugs of Limited Commercial Value within the US National Institutes of Health (NIH). What is significant about Holtzman's Bill in relation to the orphan drug problem was that it initiated a series of congressional hearings on this topic chaired by Henry A. Waxman (United States Congress 1981). These hearings provided an important venue for representatives from patients' groups such as National Myoclunus Foundation, the 
Tourrette Syndrome Association and the National Huntington's Disease Association to provide testimony. Their testimony helped to raise awareness of the plight of persons affected by rare diseases and the lack of treatments for their conditions. As the Hearings also gave an opportunity for representatives from the pharmaceutical industry and the FDA to testify, it created an important forum for the development of knowledge around a previously marginalised problem.

The testimony presented by patients at the Hearings fit into a dominant "drug lag" discourse present in the United States from the early 1970s to mid-1980s (Daemmrich \& Krücken 2000). This discourse suggested that stringent FDA procedures led to lengthy delays in the marketing of new drugs in comparison to other countries, causing unwarranted suffering and loss of life to American patients. The claims made by patients at the Hearings aligned themselves to this discourse through the suggestion that the lengthy and costly procedures present at the FDA for approving drugs further discouraged pharmaceutical companies from investing in the development or marketing of drugs intended for small patient populations. Patients' groups, academic scientists and the pharmaceutical industry often pointed to the 1962 Kefauver-Harris Amendments to the Food and Drug Act as being responsible for these regulatory delays. These amendments were introduced due to the thalidomide disaster. In response to this disaster, the FDA, alongside authorities in a number of countries began to require greater safety and efficacy data based on adequately conducted clinical trials prior to the approval of a drug for sale (Asbury 1985; Daemmrich \& Krücken 2000; Wiktorowicz 2003).
One of the consequences of these amendments was that it increased drug development times and costs. Based on the claim that pharmaceutical companies did not have sufficient economic incentives to develop or market drugs targeted at small patient populations, patients' groups proposed that a series of grants or subsidies were required to stimulate industry to develop these types of drugs. Patients' groups further shaped their claims about orphan drugs in a language appropriate to a Reaganite era. They argued that orphan drugs would allow individuals affected by rare diseases to exercise independence and become economically productive members of society, rather than a burden on their families or the state. Here, patients' groups often mobilised a discourse that balanced the costs of disability and welfare provision in contradistinction to the social benefits of "putting people back to work" and the costs of drug treatment (see statements by Abbey Myers, Jack Klugman and MS Society, United States Congress 1981). By extending the "drug lag" discourse to incorporate orphan products, proposing potential solutions to the orphan drug problem, and by highlighting the difficulties experienced by persons suffering from rare diseases, patients' groups were able to articulate the necessity of action on the behalf of government and industry to resolve this issue.

The claims made by patients' groups that the pharmaceutical industry was failing to meet the therapeutic needs of persons affected by rare disorders found support in a survey conducted as part of the Congressional hearings (Asbury 1985). One of the key findings of this survey was that out of a total of 35 drugs that the pharmaceutical industry claimed it marketed for the 
treatment of rare diseases, only 10 of these drugs had been directly developed by industry without the assistance of federal government agencies (Asbury 1985). This survey was significant in that it provided for the first time extensive knowledge of the scope of the orphan drug problem and demonstrated the failure of the market and pharmaceutical industry to meet the therapeutic needs of persons affected by rare disorders.

Aside from the congressional survey, the early 1980s witnessed the growing proliferation of knowledge in relation to the orphan drug problem through the organization of a series of conferences and the publication of a number of books (Brewer 1983; Karch 1982; Scheinberg \& Walshe 1986; Van Woert \& Chung 1985). The conferences and the publications related to them brought together representatives from patients' groups, industry and academic scientists. Through this process of dialogue and contestation, a general outline emerged about the prominent economic and regulatory factors that contributed to the orphan drug problem. These factors included the rising costs associated with bringing a new drug to market, the prospect of limited economic returns associated with drugs targeted at small patient populations, the unpatentable status of many orphan drugs, in addition to the difficulties and higher costs associated with conducting clinical trials related to rare diseases. The claims of academic scientists played an important role in supporting the struggles of patients' organizations. They helped to define the contours of the problem, illustrate the difficulties they encountered in attempting to develop promising treatments for rare conditions, and often gave moving accounts of the suffering they wit- nessed in their clinical practices. The conferences also served the important function of providing an important meeting place for representatives of different patients' organizations. Based on their mutual interest in securing the passage of orphan drug legislation, the representatives from patients' group present at a conference in Ann Arbor, Michigan on September 27-29, 1982 decided to unite their efforts and form a coalition known as the National Organisation for Rare Disorders (Brewer 1983). The formation of this coalition enabled patients' groups to lobby more effectively for the passage of the Orphan Drug Act.

Throughout the entire process of the negotiation of the orphan drug bill, patients' groups effectively used the media to give voice to their claims. Through a fortuitous twist of fate, the testimony presented at the Hearings formed the basis of an episode of the popular 1980s television series Quincy M.D. Based on reading a Los Angeles Times (Maye 1980) account of the testimony presented by Adam Seligman (a sufferer of Tourette's syndrome who had to resort to smuggling the drug Pimozide from Canada to treat his condition) the producers of Quincy M.D. created an episode around the orphan drug issue (Henkel 1999; Meyers 1985). This episode aired five days before the second round of Congressional hearings that took place in relation to orphan drugs. Based on his performance, the star of Quincy M.D., Jack Klugman, received an invitation to present testimony at the hearings. His testimony drew considerable media attention to the orphan drug problem and the plight of persons affected by rare diseases. On the same day of Klugman's testimony, the Pharmaceutical Manufacturers Association of America announced that it was 
creating a Commission on Drugs for Rare Diseases (Cohn 1981). The Quincy M.D. episode helped to spur action on the orphan drug problem from the pharmaceutical industry and enabled representatives from patients' group to gain national media attention. Through effective use of the media, the personal problems and difficulties experienced by persons affected by rare disorders became transformed into a national issue. The capability of the Quincy M.D. show to capture media attention was put to use again when a second episode on orphan drugs was created and televised at around the same time that the Orphan Drug Bill was having difficulty being approved in the U.S. Congress and Senate. Patients' groups used this episode to launch a newspaper and a telephone campaign to call the White House to encourage President Reagan to sign the Orphan Drug Bill into Law (Anonymous 1982). President Reagan signed the Orphan Drug Bill into law on January 3, 1983.

The Congressional hearings related to the Orphan Drug Bill were historically significant in finding a resolution to the orphan drug problem. In the first instance, the testimony provided by patients documented their difficulties in gaining access to treatments and led to the recognition of the special needs and difficulties faced by persons affected by rare diseases. The Hearings further noted the failure of the pharmaceutical industry, the state, and the medical profession to satisfy the needs of this population. Based on the evidence presented at the Hearings it legitimised the necessity of governmental intervention to resolve this problem. The Hearings made the orphan drug problem amenable to governmental thought and intervention by defining the scope of this prob- lem, facilitating the proposition of potential solutions, and delineating the responsibilities of the public and private sectors. The advocacy efforts of patients' groups throughout the entire process of the negotiation of orphan drug legislation was crucial to securing the collaboration of the pharmaceutical industry and the state in developing economic and regulatory incentives to foster the development and marketing of drugs intended for rare diseases. In its final form, the American Orphan Drug Act uses a range of legal and economic incentives to promote the development of orphan drugs. These incentives include 7 years of marketing exclusivity for a drug or therapy labelled as an orphan product, tax credits for clinical trial related expenses, as well as assistance with the drug application process. The legislative intention of the Orphan Drug Act is to channel, redistribute and modify some of the uncertainties and risks associated with the development of drugs aimed at small patient populations. As we will see in the following section, the Orphan Drug Act has successfully increased the number of therapies available to patients affected by rare diseases.

\section{Markets, firms and the Orphan Drug Act}

The struggle of patients' groups to pass orphan drug legislation suggestively illustrates how their efforts can have a lasting economic and regulatory legacy. As a solution to the failure of markets to develop treatments for rare diseases, the legal and economic incentives contained within the Orphan Drug Act have been successful in shaping the conduct of firms, industry, regulatory agencies in directions considered socially and economically desirable. By many accounts, the Orphan Drug 
Act is considered as one of the most successful pieces of health related legislation passed in the United States (Haffner 2006 ; Pulsinelli 1999 ; Tambuyzer 2000).

In the first instance, this legislation has shaped the conduct of firms as can be judged by the dramatic increase in the number of therapies marketed to treat rare and life threatening conditions. Secondly, as a governmental technology for encouraging the development of rare disease treatments, the American Orphan Drug Act has been adopted as a policy model by other countries and regions. Lastly, the impact of the Orphan Drug Act in shaping drug development markets can be evaluated by the growing numbers of firms that specialise in the development of treatments for rare diseases. What is significant about the provisions contained within the Orphan Drug Act is that they have effected a revaluation of rare diseases: previously these illnesses were considered to be of limited commercial value, now they are considered a potentially profitable market sector.

The Orphan Drug Act (ODA) has had an influence on the research and investment decisions of the drug development industry. By removing some of the risks and uncertainties previously associated with the development of drugs targeted at small patient populations, the ODA has positively shaped the kinds of illnesses and patient populations which private industry decides to treat or cure. One measure used to evaluate the success of this legislation is the number of orphan drug marketed since 1982. In contrast to the 35 orphan drugs on the market in the 1970s, since the passage of orphan drug legislation, 285 of these drugs are now marketed (Haffner et al. 2002).
Commercial interest in these drugs is further measured by the number of applications made for orphan drug designation - a figure which presently stands at 1917 (Haffner et al. 2002). The significant growth in the number of orphan drugs marketed can be attributed to the growth of the biotechnology industry from the 1980s onwards. As many rare diseases are genetic in origin, the legal and economic incentives contained within the Act provide a stimulus to an emergent biotechnology industry (Haffner et al. 2002; Meyers 1992; Tambuyzer 2000).

The ODA has had a significant impact on the biotechnology industry. Although the ODA was designed to provide a range of incentives to the pharmaceutical industry, its greatest impact has been on the biotechnology industry. The ODA is often credited with fomenting the growth and development of this industrial sector. For many start-up biotechnology companies, orphan product designation is often seen as instrumental to securing venture capital investment due to the prospect of 7 years of marketing exclusivity and the tax credits associated with clinical trial related expenses. The significance of the ODA to this nascent industry is best captured in an article in Nature Biotechnology which report that " $56 \%$ biotechnology products launched between 1982 and 2000 were first approved for orphan drug indications..." (Ashton 2001; see also Haffner et al. 2002). The ODA has effectively shaped the conduct of particular companies who have found a niche in satisfying unmet medical needs and corporate bottom lines. The ODA has not only shaped the conduct of markets and firms, it has contributed significantly to the health of populations affected by rare diseases. 
By acting upon the economic circumstances surrounding the development of drugs for small patient populations, it is often claimed that the ODA has augmented the health of the estimated 20-25 million Americans affected by rare diseases. It is suggested that 14 million Americans have benefited from new treatments for their rare illnesses (Haffner et al. 2002). According to Marlene Hafner (2003: 374), 85 percent of orphan designations are for the treatment of serious or life threatening conditions such as rare forms of cancer or metabolic disorders.

What I believe to be of further significance is how the Act has extended the clinical reach of medicine to conditions where no viable treatment option previously existed. Patients' groups, industry and the FDA argue that the success of the ODA in promoting the development of new treatments and contributing to human well being has led to the adoption of this legislation in locales outside the United States.

The American Orphan Drug Act has further served as a model for the development of similar legislation in Singapore, Japan, Australia and most recently, the European Union. As a governmental model, the Orphan Drug Act is valued since it combines a programme for the achievement of public health objectives, in addition to promoting innovation in the nationally strategic important area of biotechnology. The adoption of this legislation in other countries involves recognition that the market fails to develop treatments for rare diseases in the absence of state intervention. It further involves a re-prioritisation of the health needs of persons affected by rare disorders. In the case of the European Union, patients' group lobbied hard to get orphan drug legislation approved and their efforts received assistance from NORD.

Despite the rather rosy picture I have painted, the creation of favourable market conditions for the development of rare disease treatments is not without a number of problems. The Orphan Drug Act was initially developed to encourage firms to develop therapies where there was no reasonable prospect of them making a reasonable return on their investment, let alone significant profits. However, some orphan drugs are amongst the most expensive in the world. Let me take the example of drug developed by Genzyme known as Cerezyme. The average annual cost of treating a patient with Cerezyme varies from $\$ 70,000$ USD to $\$ 300,000$ USD dependent on dosage and body weight. Considering that a treatment such as Cerezyme is required for the remainder of a patient's life it generates substantial revenues. Genzyme is not alone in producing profitable orphan drugs: Genentech's Propotin, Amgen's Epogen, and Novartis' Gleevec have all managed to make it on to the list of the top 100 selling drugs. It is important to emphasise that the vast majority of orphan drugs have sales in the region of \$15-20USD million and are not profitable. The topic that I would like to move on to discuss is how the high cost of a high cost of a small number of orphan drugs raises the more serious problem of how national health care systems are able to pay for these treatments.

\section{Pharmacoeconomics, orphan drugs and contemporary patient activism}

Within the field of rare disease activism one of the 
key sites of struggle that has emerged in recent years is around access to medicines. From the mid 1980s onwards, European and North American states became increasingly concerned with reducing their healthcare expenditures in the face of an exponential increase in the number of diseases that can be treated by either pharmaceutical or biological means. The high cost of some orphan drugs raises the question for national healthcare systems of whether the provision of these drugs to a small number of patients affected by rare diseases will adversely affect its capacity to meet the health needs of the general population. As I will endeavour to show, patient group activism around orphan drugs has shifted towards attempting to shape the administrative procedures that determine patient access to orphan drugs.

The kinds of struggle that rare disease activists now engage in are concerned with shaping the forms of clinical and economic calculation that are used to adjudicate the social distribution of health care resources amongst the population. One form of calculation used to make health care decisions is known as pharmacoeconomics. Pharmacoeconomics, as a discipline, is concerned with developing a rational set of principles to assess healthcare practices so that the most efficient use is made of limited healthcare resources.

Let me give a more practical example of pharmacoeconomic assessment based from the United Kingdom. A group of Primary Care Trusts based in the West Midlands had to decide whether to provide enzyme replacement therapies for Gaucher's diseases, Fabry's disease and MPS 1. These therapies, with some reservations, are considered clinically effective. However, these therapies are expensive. After conducting a pharmacoeconomic assessment, the authorities in the West Midlands decided not to offer these treatments to patients. The justification provided for this decision used the economic concept of opportunity costs to address the normative question of how healthcare resources should be distributed amongst different sectors of the population (Burls et al. 2005). It was suggested that when resources are devoted to high cost treatments that affect a small percentage of the population, the opportunity costs involved consist of there being less resources available to fund health interventions that offer better value for money and have a greater impact upon the health of the population (Burls et al. 2005).

Rare disease patients' group are not entirely satisfied when these types of decisions are made about the only treatments that are available for their conditions. Across the European Union and North America, patients' groups are contesting pharmacoeconomic assessments made in relation to orphan drugs. They are concerned with securing a proportion of national healthcare budgets for the treatment of rare diseases. The struggle for access to orphan drugs takes place across a number of terrains and employs a variety of tactics. Patient's organisations successfully use the media to mobilise the suffering experienced by their members for political purposes (Stockdale 1999). By highlighting the plight of patients, especially children suffering from life threatening rare diseases, who are being denied medical treatment due to cost considerations generate media interest; elicit empathy from the public ; and place significant pressure on political authorities to act immediately to save a life. The field of health and social policy constitutes 
another strategic site of struggle. A key argument that is mobilised by patients' groups is that since orphan drug legislation is aimed at promoting the development of treatments for rare diseases, it makes logical sense for the state to provide reimbursement for these drugs through the national health care system. In Europe, it is suggested that orphan drug legislation embeds the principle that persons affected by rare diseases have the same right to treatment as individuals affected by common conditions. These types of arguments extend into the field of healthcare financing: here, it is argued that although some orphan drugs are expensive, given their clinical effectiveness and the small number of patients that require them, they have a minimal impact upon overall health budgets (Kanavos \& Saka 2005). tion of patient activists, those organised around AIDS, were able to further affect changes to the regulation of pharmaceutical and the conduct of clinical trials (Epstein 1996). This model of activism has grown in scope, as witnessed by the ever-increasing formation and growth of patients' organisations and related coalitions since the 1980s. In thinking about this in relation to contemporary biopolitics, it could be said that by changing the scale of their organizational efforts, patients' organizations have managed to integrate themselves into the relays of power through which matters of health are thought about and acted upon. Through their formation into coalitions, patients' organisations have been able to assume of number of important functions in relation to the government of health.

\section{Conclusion}

The orphan drug problem can be thought of as having changed the scale and organizational form of rare disease patients' groups. In the process of attempting to enact legislation relating to the orphan drug problem, it led to the formation of a coalition of patients' groups known as the National Organisation for Rare Disorders (NORD). This coalition came about through the realisation that through binding their efforts together, patients' groups could exert a greater influence on government and the pharmaceutical industry, rather than by working individually. In the case of orphan drugs, the coalition of diverse patients' groups that mobilised around this problem succeeded in changing the landscape of pharmaceutical markets by creating a series of incentives for companies to sponsor therapies through the FDA approval process. In the 1980 s, a different coali- 


\section{$R \cdot \dot{E} \cdot F \cdot \dot{E} \cdot R \cdot E \cdot N \cdot C \cdot E \cdot S$}

ANONYMOUS (1982) «Drug development act faces veto», Washington Post, Washington.

ASBURY, C.H. (1985) Orphan drugs: medical versus market value. Lexington MA: Lexington Books.

ASHTON, G. (2001) "Growing pains for biopharmaceuticals", Nature Biotechnology, 19, 307-311.

BREWER, G.J. (1983) Orphan drugs and orphan diseases : clinical realities and public policy, New York: Alan R. Liss.

BURLS, A., AUSTIN, D. and MOORE, D. (2005) "Commissioning for rare diseases : view from the frontline", British medical journal, 331, 1019-1021.

COHN, V. (1981) “TV's 'Quincy’ tells hill about rare diseases", Washington Post, Washington.

DAEMMRICH, A. and KRÜCKEN, G. (2000)

"Risk versus risk : decision-making dilemmas of drug regulation in the United States and Germany", Science as Culture, 9, 505-534.

EPSTEIN, S. (1996) Impure Science: AIDS, Activism, and the Politics of Knowledge. Berkeley CA: University of California Press.

HAFFNER, M.E. (2003) "The current environment in orphan drug development", Drug Information Journal, 37, 373-379.

HAFFNER, M.E. (2006) "Adopting orphan drugs: two dozen years of treating rare diseases", New England journal of medicine, 354, 445-447. HAFFNER, M.E., Whitley, J. and Moses, M. (2002) "Two decades of orphan drug development”, Nature Reviews Drug Discovery, 1, 821-825.

HENKEL, J. (1999) "How TV Launched the
Orphan Drug law", FDA Consumer Magazine. KANAVOS, P. and SAKA, Ö. (2005) "Providing Access to Modern Treatments and Influencing Policy in Orphan Diseases : the International Experience and Evidence from the UK", LSE Health and Social Care Discussion Paper Number 20, London : London School of Economics.

KARCH, F. (1982) Orphan drugs. New York : M. Dekker.

MAYE, J. (1980) "L.A. victim of rare disease", Los Angeles Times, Los Angeles.

MEYERS, A.S. (1985) “The consumer's role in development of orphan drugs", in Van Woert, M.H. and Chung, E. (eds.) Cooperative approaches to research and development of orphan drugs, New York : Alan R. Liss.

MEYERS, A.S. (1992) "The impact of orphan drug regulation on patients and availability", Food and Drug Law Journal, 47, 9-14.

PULSINELLI, G.A. (1999) “The Orphan Drug Act: What's right with it", Santa Clara Computer and High Tech Law Journal, 15, 299-345. RABEHARISOA, V. (2003) "The struggle against neuromuscular diseases in France and the emergence of the "partnership model" of patient organisation", Social Science \& Medicine, 57, 2127-2136.

SCHEINBERG, I.H. and WALSHE, J.M. (1986) Orpan diseases and orphan drugs, Manchester : Manchester University Press.

STOCKDALE, A. (1999) "Waiting for the cure: mapping the social relations of human gene therapy research", Sociology of health \& illness, 21, 579-596.

TAMBUYZER, E.T. (2000) "The European Orphan Medicinal Products Regulations and the biotechnology-basedindustryinEurope", Journal 
of Commercial Biotechnology, 6, 340-344. UNITEDSTATESCONGRESS(1981)Hearings before the Subcommittee on Health and the Environment of the Committee on Energy and Commerce, House of Representatives, NinetySeventh Congress, Orphan Drugs, HR 1663, March 9, 1981. Washington : U.S. G.P.O.

VAN WOERT, M.H. (1983) "Myoclonus and L-5-Hydoxytryptophan (L-5HTP)", in Brewer, G.J. (ed.) Orphan drugs and orphan diseases: clinical realities and public policy, New York : Alan R. Liss.

VAN WOERT, M.H. and CHUNG, E. (1985) Cooperative approaches to research and development of orphan drugs, New York : Alan R. Liss.

WIKTOROWICZ, M.E. (2003) "Emergent Patterns in the Regulation of Pharmaceuticals : Institutions and Interests in the United States, Canada, Britain, and France", Journal of Health Politics, Policy and Law, 28, 615-658.

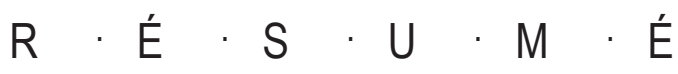

This paper examines the forms of political and scientific activism that have emerged around orphan drugs from the late 1970s to the contemporary present. This paper documents the role of a number of patient's groups in fostering the passage of the American Orphan Drug Act. The paper then moves on to consider the extent to which this legislation has encouraged the pharmaceutical and biotechnology industry to develop treatments for rare diseases. Lastly, the paper examines some of the contemporary biopolitical problems which orphan drugs pose in terms of the high cost of a number of these types of therapies which limits patient access to orphan drugs.

Drogues orphelines, militantisme médical et soins de santé contemporains

Cette contribution analyse les formes de militantisme politique et scientifique qui ont émergé autour des médicaments orphelins depuis la fin des années 70 jusqu'à aujourd'hui. Plus particulièrement, cet article présente le rôle de différents groupes de patients qui ont favorisé le passage de l'American Orphan Drug Act. Ensuite, il discute dans quelle mesure la législation a encouragé l'industrie pharmaceutique et biotechnologique à développer des traitements pour les maladies rares. Enfin, il analyse quelques unes des questions biopolitiques contemporaines posées par les drogues orphelines, notamment le problème du coût élevé de ces formes de thérapies qui limite l'accès du patient aux drogues orphelines. 
